\title{
Carboxymethylated Sulfated Heteroexopolysaccharide from a Haloarchaeal Strain as Potential Biomolecule for Harmless Adjuvant Therapy in Cancer Treatment
}

\author{
Habib Chouchane $\left(\mathbb{D},{ }^{1}\right.$ Afef Najjari, ${ }^{2}$ Hanene Cherif $\left(\mathbb{D},{ }^{1}\right.$ Mohamed Neifar $\left(\mathbb{D},{ }^{1}\right.$ \\ Haitham Sghaier $\left(\mathbb{1},,^{1,3}\right.$ Hadda Imene Ouzari $\left(\mathbb{D},{ }^{2}\right.$ and Ameur Cherif $\mathbb{C}^{1}$ \\ ${ }^{1}$ Univ. Manouba, ISBST, LR11-ES31 BVBGR, Biotechpole Sidi Thabet, 2020, Ariana, Tunisia \\ ${ }^{2}$ Université de Tunis El Manar, Faculté des Sciences de Tunis, LR03ES03 Laboratoire de Microbiologie et Biomolécules Actives, \\ 2092 Tunis, Tunisia \\ ${ }^{3}$ Laboratory "Energy and Matter for Development of Nuclear Sciences" (LR16CNSTN02), \\ National Center for Nuclear Sciences and Technology (CNSTN), Sidi Thabet Technopark, Sidi Thabet 2020, Tunisia \\ Correspondence should be addressed to Habib Chouchane; chouchane12habib@gmail.com
}

Received 22 October 2019; Revised 18 December 2019; Accepted 8 January 2020; Published 19 February 2020

Guest Editor: Ziwen Jiang

Copyright (c) 2020 Habib Chouchane et al. This is an open access article distributed under the Creative Commons Attribution License, which permits unrestricted use, distribution, and reproduction in any medium, provided the original work is properly cited.

\begin{abstract}
This study explored the possible use of a microbial carboxymethylated sulfated heteroexopolysaccharide (CS-hEPS) as a potential anticancer agent. The investigation was carried out through antioxidant, antifatigue, and antiproliferative activities. Antioxidant potential including scavenging DPPH and hydroxyl radical activities and reducing power was evaluated. Antifatigue activity was determined by assessing the endurance of mice using the forced swimming test. Following 30 days of CS-hEPS oral treatment at different doses, biochemical parameters related to fatigue such as lactic dehydrogenase (LDH), serum urea nitrogen (SUN), and hepatic glycogen (HG) contents were measured. Antitumor activities were investigated against human cancer liver and myelogenous leukemia cells. Results showed that CS-hEPS possesses notable antioxidant, antifatigue, and antitumor effects. CS-hEPS significantly inhibited the proliferation of leukemia $(86.6 \pm 0.32 \%)$ and cancer liver $(58.6 \pm 0.43 \%)$ cells. CS-hEPS are promising natural antioxidant, antifatigue, and antitumor harmless adjuvant materials that could be applied in human cancer therapy.
\end{abstract}

\section{Introduction}

Extreme environments are valuable reservoir for rugged microorganisms with the ability to produce unusual macromolecules with particular biological properties. Microbial exopolysaccharides (mEPS), composed of numerous monosaccharide units linked by glycosidic bonds in linear or branched chains, are considered as one class of these active biomacromolecules. mEPS are recognized as important biological response modifiers $[1,2]$. Their biological activities are greatly influenced by their characteristics such as molecular weight, charge density, monosaccharide composition, acidic fraction, types of glycosidic linkage, and substitution groups [3-5]. Specifically, sulfated polysaccharides have been proved to possess potent antitumor and antioxidant activities that made them gain increasing attention as potential new natural therapeutic materials and good substitutes for synthetic agents $[1,4]$. It has been found that mEPS produced by Bacillus amyloliquefaciens show significant therapeutic activities against gastric tumors [4]. Similarly, mEPS of Lactobacillus casei 01 exhibited an antiproliferation effect on human colon cancer cells HT-29 with a significant dose-dependent effect [5]. Murofushi et al. [6] noticed that the acidic fraction from Lactobacillus plantarum N14 (LP14) strongly stimulated the $\mathrm{NF}-\mathrm{kB}$ pathway in transfectant cells and decreased the production of proinflammatory cytokines. The presence of high content of uronic acid gave mEPS interesting properties to be used in regenerative medicine and tissue engineering. Priyanka et al. showed that mEPS produced by Nitratireductor sp. with $7.08 \%$ uronic acid and $2.68 \%$ sulfate functional group 
constitute a promising drug for brain tumors as they can inhibit Akt/PI3K pathway through their anionic charged EPS by binding to the epidermal growth factor (EGF) secreted by the tumor. This correlates with the findings of Liu et al. that anionically charged EPS can prevent EGF receptor phosphorylation [7, 8]. Using the MTT (3-(4,5-dimethylthiazol-2yl)-2,5-diphenyltetrazolium bromide) assay, Priyanka et al. [7] demonstrated that mEPS produced cytotoxicity against U87MG glioblastoma cells and showed an $\mathrm{IC}_{50}$ value of $234.04 \mu \mathrm{g} \cdot \mathrm{ml}^{-1}$.

Additionally, side effects and symptoms are frequent challenges occurring during cancer chemoradiotherapy treatment of patients. One of the most frequently reported symptoms is fatigue [9, 10]. As defined by Miller et al., fatigue is a state of decreased energy level fluctuating from tiredness to exhaustion that can interfere with the ability to accomplish daily tasks and negatively impacts quality of life [11]. Patients undergoing cancer treatment have significantly higher fatigue levels when compared to patients without a chronic health condition [12]. There is scientific evidence that chemotherapy (platinum coordinating complexes, 5-fluorouracil, alkylating agents), hormonotherapy (tamoxifen, aromatase inhibitors), and radiotherapy (ionizing radiation) used in cancer treatment cause substantial oxidative stress (OS) in nontargeted tissues [13, 14]. This OS plays a pivotal role in many pathological processes, mainly fatigue. OS occurs when the balance between reactive oxygen species (ROS) and antioxidant defenses is disrupted due to an accumulation of ROS or a depletion of antioxidant defenses. This disruption initiates a chain of reactions that cause cell death [15]. Antioxidants may alleviate the adverse effects of ROS and fatigue caused by chemo-hormonoradiotherapies.

Synthetic antioxidants such as butylated hydroxy toluene and butylated hydroxy anisole are commonly authorized for use in food to cope with OS. However, because of the controversy surrounding their safety and carcinogenic potential $[16,17]$, there is a growing demand for natural molecules with similar antioxidant and antifatigue effectiveness $[18,19]$. In this context, some mEPS have demonstrated an important role as natural free radical scavengers for the prevention of oxidative damage and fatigue [1].

The present study illustrates for the first time the benefits of using a natural carboxymethylated sulfated polysaccharides, produced by a haloarchaeal strain, Halogeometricum borinquense 52, isolated from a Tunisian atypical environment, as antioxidant, antifatigue, and antitumor adjuvants in cancer therapy.

\section{Materials and Methods}

2.1. Inoculum Preparation and Microorganism Cultivation. $H$. borinquense 52 was isolated from hypersaline sediments collected from Chott el-Djerid (Southern Tunisia). It was identified according to its $16 \mathrm{~S}$ rDNA sequences analysis [20]. $H$. borinquense was grown and maintained on an optimized DSC-97 medium containing (g/L) $7.32 \mathrm{~g}$ glucose, $1.25 \mathrm{~g}$ casamino acid, $150 \mathrm{~g} \mathrm{NaCl}, 3.0 \mathrm{~g}$ trisodium citrate, $2.0 \mathrm{~g} \mathrm{KCl}$,
$20.0 \mathrm{~g} \mathrm{MgSO}_{4} .7 \mathrm{H}_{2} \mathrm{O}, 0.023 \mathrm{~g} \mathrm{FeCl}_{2}$, and $15 \mathrm{~g}$ agar-agar. The $\mathrm{pH}$ was adjusted to 7.4. The archaeon was grown at this medium at $45^{\circ} \mathrm{C}$ for 48 hours (h).

2.2. CS-hEPS Production and Purification. The optimized DSC-97 medium $(250 \mathrm{ml})$ was inoculated with $1.5 \mathrm{ml}$ of pregrown $H$. borinquense 52 . After six days of incubation at $45^{\circ} \mathrm{C}$, culture samples were centrifuged (12.000 revolutions per minute $(\mathrm{rpm}), 20 \mathrm{~min})$. Three volumes of cold $\left(4^{\circ} \mathrm{C}\right)$ ethanol were added to one volume of culture supernatants and the mixtures were stored overnight at $4^{\circ} \mathrm{C}$. The precipitate in the centrifuging tube was rinsed with distilled water, filtered, and then dried at $45^{\circ} \mathrm{C}$ using rotavap. Proteins were removed from CS-hEPS as described in our previous study [21]. For in vivo activities, lyophilized CS-hEPS were further purified using a Sephadex G-100 column $(2.6 \mathrm{~cm} \times 50 \mathrm{~cm})$, and the column was eluted with $0.01 \mathrm{M}$ $\mathrm{NaCl}$ solution at a flow rate of $1 \mathrm{~mL} / \mathrm{min}$ [22].

2.3. Functional Groups and Carbohydrate, Uronic Acid, Sulfate, and Monosaccharide Contents of Purified CS-hEPS. Purified CS-hEPS were checked for their carbohydrate content as described by Chaplin and Kennedy [23] with some modifications. A CS-hEPS solution $(0.2 \mathrm{~mL})$ was mixed with $0.2 \mathrm{~mL}$ phenol solution $(5.0 \%$, w/v), and $1.0 \mathrm{~mL}$ concentrated $\mathrm{H}_{2} \mathrm{SO}_{4}$ was added to the reaction mixture. Distilled water and glucose were used as a blank and a standard, respectively, for plotting a calibration curve. The total carbohydrate in CS-hEPS was then estimated, as glucose equivalents, by reading the absorbance of the obtained solution against the glucose standard curve (supplementary data, Figure 1(A)). The absorbance was measured at $492 \mathrm{~nm}$ with a spectrophotometer (Analytic Jena SPEKOL 2000) after incubation at room temperature for $30 \mathrm{~min}$.

Uronic acid content was determined by the method of Blumenkrantz and Asboe-Hansen [24] with modifications. A CS-hEPS solution $(200 \mu \mathrm{L})$ was mixed with $1.2 \mathrm{~mL}$ of $0.0125 \mathrm{M}$ sodium tetraborate solution in concentrated $\mathrm{H}_{2} \mathrm{SO}_{4}$. The mixture was homogenized by vortex and then cooled in ice. After incubation at $100^{\circ} \mathrm{C}$ for $5 \mathrm{~min}$, the mixture was cooled quickly and then added to $20 \mu \mathrm{L}$ of metahydroxydiphenyl at $0.15 \%$ in $\mathrm{NaOH}(0.5 \%)$. It is worth noting that the colorimetric reaction is sensitive to interference from neutral sugars which are brown in the presence of $\mathrm{H}_{2} \mathrm{SO}_{4}$. This interference was minimized by treating CShEPS with sulfamate (sulfamic acid/potassium sulfamate $4 \mathrm{M} \mathrm{pH} \mathrm{1.6)} \mathrm{before} \mathrm{acid} \mathrm{hydrolysis.} \mathrm{The} \mathrm{uronic} \mathrm{acid} \mathrm{content}$ in CS-hEPS was estimated, as glucuronic acid equivalents, by reading the absorbance of the obtained solution against the glucuronic acid standard curve (supplementary data, Figure 1(B)). The absorbance was measured at $520 \mathrm{~nm}$ with a spectrophotometer (Analytic Jena SPEKOL 2000) after incubation at room temperature for $30 \mathrm{~min}$.

The turbidimetric method [25] was applied to evaluate the sulfate content of CS-hEPS after $\mathrm{HCl}$ hydrolysis $(5 \mathrm{mg}$ of CS-hEPS with $0.2 \mathrm{~mL}$ of $1 \mathrm{M} \mathrm{HCl}$ for $6 \mathrm{~h}$ at $110^{\circ} \mathrm{C}$ ). The obtained hydrolysate was added to $3.8 \mathrm{~mL}$ trichloroacetic acid $(3.0 \% \mathrm{w} / \mathrm{v})$ and $1.0 \mathrm{~mL}$ of a barium chloride-gelatin 
solution and mixed. $\mathrm{HCl}$ was used as a blank. Sulfate content was estimated, as $\mathrm{K}_{2} \mathrm{SO}_{4}$ equivalents, by reading the absorbance against a standard curve prepared with a solution of $\mathrm{K}_{2} \mathrm{SO}_{4}$ (supplementary data, Figure $1(\mathrm{C})$ ). The absorbance was measured at $360 \mathrm{~nm}$ after incubation at room temperature for $15 \mathrm{~min}$.

For the assessment of the monosaccharides content, $20 \mathrm{mg}$ of purified CS-hEPS was dissolved in trifluoroacetic acid (TFA) ( $1 \mathrm{~mL}, 3 \mathrm{M}$ ) and incubated for $2 \mathrm{~h}$ and $30 \mathrm{~min}$ at $110^{\circ} \mathrm{C}$. After cooling, the reaction mixture was centrifuged and evaporated to remove TFA.

An HPLC-RID (Agilent Technologies 1200 series) equipped with a phenomenex Luna aminated $\left(\mathrm{NH}_{2}\right)$ column $(5 \mu \mathrm{m}, 250 \times 4.6 \mathrm{~mm})$ was used with acetonitrile : water $(3: 1)$ as the mobile phase. Hydrolysed CS-hEPS and $20 \mathrm{mg}$ of each standard (arabinose, fructose, galactose, glucose, mannose, rhamnose, ribose, xylose, maltose, saccharase, and lactose) were dissolved in $1 \mathrm{~mL}$ of distilled water. A flow of $1 \mathrm{~mL} / \mathrm{min}$ and $20 \mu \mathrm{L}$ injections were used at $25^{\circ} \mathrm{C}$.

To determine the functional groups of purified CS-hEPS, Bruker Vertex 70 FTIR spectrometer was used to obtain a Fourier Transform InfraRed (FTIR) spectrum over a wave range of $400-4000 \mathrm{~cm}^{-1}$ at 64 scans, $4 \mathrm{~cm}^{-1}$ wave number, and resolution transmission mode.

2.4. CS-hEPS In Vitro Antioxidant Activity. For determining the CS-hEPS in vitro antioxidant activity, ascorbic acid, at various concentrations, was used as a reference. Experiments were performed in triplicate and averaged.

2.4.1. CS-hEPS DPPH Radical Scavenging Activity. The free radical scavenging activity of the CS-hEPS was evaluated by the 1,1-diphenyl-2-picrylhydrazyl (DPPH) test according to the method described by Zhang et al. [26]. Different concentrations of CS-hEPS $(0.5-3 \mathrm{mg} / \mathrm{mL})$ were mixed with DPPH ( $0.2 \mathrm{mM}$ in $95 \%$ ethanol, $2 \mathrm{~mL})$. The mixture was then shaken at $120 \mathrm{rpm}$ vigorously and kept at room temperature for $30 \mathrm{~min}$. Equation (1) was used to determine the DPPH scavenging rate (DSR).

$$
\operatorname{DSR}(\%)=\frac{\left[1-\left(A_{i}-A_{j}\right)\right]}{A_{0}} \times 100 \%,
$$

where $A_{i}$ is the absorbance of the sample with $\mathrm{DPPH}, A_{j}$ is the absorbance of the sample without $\mathrm{DPPH}$, and $A_{0}$ is the absorbance of pure DPPH at $517 \mathrm{~nm}$.

\subsubsection{CS-hEPS Hydroxyl Radical Scavenging Activity.} The protocol of $\mathrm{Wu}$ et al. [27] was used to evaluate the hydroxyl radical $(\mathrm{HO} \bullet)$ scavenging activity of haloarchaeal CS-hEPS. Equal volume $(0.5 \mathrm{ml})$ of 1,10 -phenanthroline $(7.5 \mathrm{mM})$ and $\mathrm{FeSO}_{4}(7.5 \mathrm{mM})$ was mixed with $0.5 \mathrm{ml}$ of sodium phosphate buffer $(0.2 \mathrm{M})$. Then, $1 \mathrm{~mL}$ of the CS-hEPS at various concentrations $(0.5-3 \mathrm{mg} / \mathrm{mL})$ and $\mathrm{H}_{2} \mathrm{O}_{2}(0.1 \%$, $0.5 \mathrm{~mL}$ ) were added. The mixture was incubated for $60 \mathrm{mn}$ at $37^{\circ} \mathrm{C}$. Equation (2) was used to evaluate the hydroxyl radical scavenging rate (HSR).

$$
\mathrm{HSR} \%=\frac{\left[\left(H_{s}-H_{0}\right) \times 100 \%\right]}{H_{c}-H_{0}},
$$

where $H_{s}$ is the absorbance of the sample, $H_{0}$ is the absorbance of the blank solution using distilled water, and $H_{c}$ is the absorbance of a control solution in the absence of $\mathrm{H}_{2} \mathrm{O}_{2}$. All absorbances were measured at $510 \mathrm{~nm}$ using an analytic Jena SPEKOL 2000 spectrophotometer.

\subsubsection{CS-hEPS Superoxide Radical Scavenging Activity.} The scavenging activity of CS-hEPS against superoxide radical $\left(\mathrm{O}_{2}{ }^{-}\right)$was determined according to the protocol described by Qiao et al. [28]. All needed solutions (nicotinamide adenine dinucleotide $(\mathrm{NADH})$, nitroblue tetrazolium (NBT), phenazine methosulphate (PMS), and EPS samples) were dissolved in 0.1 M PBS ( $\mathrm{pH} 7.4$ ). Then, equal volumes $(1.0 \mathrm{~mL})$ of $156 \mu \mathrm{mol} / \mathrm{L}$ NBT solution and $468 \mu \mathrm{mol} /$ $\mathrm{L} \mathrm{NADH}$ solution were mixed with CS-hEPS at various concentrations $(0.5-3 \mathrm{mg} / \mathrm{mL})$. The addition of $1.0 \mathrm{~mL}$ of $60 \mu \mathrm{mol} / \mathrm{L}$ PMS to the mixture indicated the initiation of the reaction. After $5 \mathrm{~min}$ incubation at room temperature, absorbance at $560 \mathrm{~nm}$ was read against PBS (0.1M, pH 7.4) used as a blank. Equation (3) was used to evaluate the superoxide radical scavenging rate (SSR):

$$
\operatorname{SSR}(\%)=\frac{\left[S_{0}-\left(S_{1}-S_{2}\right)\right]}{S_{0}} \times 100,
$$

where $S_{0}$ is the absorbance of the control (PBS instead of sample solution), $S_{1}$ is the absorbance of the sample, and $S_{2}$ is the absorbance of the sample under identical conditions.

2.5. CS-hEPS In Vivo Antifatigue Effect. One hundred mice were randomly divided into five groups based on body weight after one week accommodation ( $n=20$ mice/group; equal numbers of male and female) and orally treated with $0.5 \mathrm{~mL}$ of saline solution (serving as a negative control group), $0.5 \mathrm{ml}$ of ascorbic acid (serving as positive control group), and $0.5 \mathrm{ml}$ of purified CS-hEPS, dissolved in saline solution, at doses of 100,150 , and $200 \mathrm{mg} / \mathrm{kg}$ once daily for 30 days.

The exhaustive swimming test (EST) was carried out in a cubic container ( $30 \mathrm{~cm}$ deep water) at room temperature as described by Huang et al. [29]. At the end of experiments, mice were left to rest for one day. As an adaptive training before EST, mice were made to swim for 2 min twice per week. The exhaustive swimming time was used as an index of the increase in exercise tolerance. The mice were considered to be exhausted when they failed to rise to the surface to breathe after $10 \mathrm{~s}$. After swimming, blood was collected from mice orbit to determine LDH and SUN contents. The livers of the mice were taken to determine HG levels. Biochemical parameters were assayed by using lactate dehydrogenase ELISA Kit (Abcam), blood urea nitrogen ELISA Kit, and Glycogen Assay Kit (Abcam) according to the manufacturer's protocols. 
2.6. CS-hEPS In Vitro Antitumoral Activity. To study the antitumor activity of CS-hEPS from the haloarchaeal strain $H$. borinquense, two types of human cancer cells were used (liver cancer HepG and myelogenous leukemia cells K562). They were both cultured in DMEM medium supplemented with $10 \%(\mathrm{v} / \mathrm{v})$ fetal bovine serum. One hundred $\mathrm{U} / \mathrm{mL}$ penicillin and streptomycin were added to the culture medium maintained at $37^{\circ} \mathrm{C}$ in a $5 \% \mathrm{CO}_{2}$ atmosphere. The antitumor activities of various concentrations of CS-hEPS $(0,50,100,200,400$, and $600 \mu \mathrm{g} / \mathrm{mL})$ on HepG-2 and K562 cells in vitro were evaluated using the MTT assay according to Chen et al. [30].

2.7. Statistical Analyses. Data were analyzed using SPSS software. One-way analysis of variance and multiple comparisons were used to evaluate differences among groups. $P$ value $<0.05$ was considered to indicate a statistically significant difference.

\section{Results}

3.1. Preliminary Characterization of Purified CS-hEPS. Based on the calibration curve $\mathrm{OD}=f$ (concentration of glucose) already drawn (supplementary data, Figure 1(A)), we estimated the total carbohydrate content of the purified CS-hEPS. The absorbance of the solution was 0.320 which corresponds to a concentration of $0.038 \mathrm{mg} / \mathrm{ml}$ glucose equivalent. The value obtained was converted with the initial concentration of CS-hEPS (45 mg/L) giving a total carbohydrate content of $84.2 \%$. Using the same approach and the corresponding calibration curves (supplementary data, Figures 1(B) and 1(C)), the amounts of uronic acid and sulfate in CS-hEPS (45 mg/L) were determined as $12.5 \%$ and $3.2 \%$ with $\mathrm{OD}=0.04$ and 0.13 , respectively.

Purified CS-hEPS showed a negative response to the Bradford test and no absorption at 260 or $280 \mathrm{~nm}$ in the UV spectrum, which indicates the absence of nucleic acids and proteins.

HPLC-RID analysis (Figure 1) showed that CS-hEPS from $H$. borinquense was a heteropolysaccharide composed of the three monosaccharides, rhamnose, fructose, and glucose.

The FTIR spectrum at $4000-400 \mathrm{~cm}^{-1}$ of CS-hEPS is represented in Figure 2. All obtained peaks were in agreement with typical absorption data of a polysaccharide. The large absorption peak observed at around $3160 \mathrm{~cm}^{-1}$ indicated the presence of intensive hydroxyl groups $-\mathrm{OH}$. In addition, the absorption bands at 1598 and $1310 \mathrm{~cm}^{-1}$ indicated the existence of two functional carboxymethyl groups of $-\mathrm{COOH}$ and $-\mathrm{CH}_{2}-$. The band within the $1124 \mathrm{~cm}^{-1}$ region was attributed to the vibration of $\mathrm{C}-\mathrm{O}-\mathrm{C}$ band. The peaks around $1066-902 \mathrm{~cm}^{-1}$ were related to methoxyl groups, typical group of sugar derivatives, and uronic acid. This was in accordance with the results of uronic acid analysis. Moreover, bands found at $842-790 \mathrm{~cm}^{-1}$ and $1216-1266 \mathrm{~cm}^{-1}$, which represented functional groups of $\mathrm{C}-\mathrm{S}-\mathrm{O}$ and $\mathrm{S}-\mathrm{O}$, indicated the presence of sulfated groups in the polysaccharide. Bands at 694 and $486 \mathrm{~cm}^{-1}$ represented absorption peaks for the aromatic - $\mathrm{CH}$ bending vibration. In summary, analyses demonstrated that the polysaccharide from the haloarchaeal strain is a carboxymethylated sulfated heteroexopolysaccharide (CS-hEPS) with abundant functional groups.

3.2. In Vitro Antioxidant Activities of $H$. borinquense CS$h E P S$. The in vitro antioxidant ability of CS-hEPS was evaluated through the detection of the scavenging rates of $\mathrm{DPPH},(\mathrm{HO} \bullet)$, and $\left(\mathrm{O}_{2} \cdot{ }^{-}\right)$radicals. Results are summarized in Figure 3. The DPPH free radical scavenging activity of the CS-hEPS is shown in Figure 3(a) and compared with ascorbic acid as a positive control. The scavenging activity increased with the concentration from 0.5 to $2.5 \mathrm{mg} / \mathrm{mL}$ of the CS-hEPS. It was slightly lower than that of ascorbic acid at the concentration of $2.5 \mathrm{mg} / \mathrm{mL}$. When the concentration was higher than $1.5 \mathrm{mg} / \mathrm{mL}$, the $\mathrm{DPPH}$ radical scavenging activity increased slightly. The $\mathrm{IC}_{50}$ of $\mathrm{DPPH}$ radical scavenging for the EPS was $2.5 \mathrm{mg} / \mathrm{ml}$. Additionally, from Figures 3(b) and 3(c) we observed that CS-hEPS exhibited a concentration-dependent scavenging activity, for both hydroxyl and superoxide radicals, with CS-hEPS $\mathrm{IC}_{50}$ equal to 1.5 and $0.5 \mathrm{mg} / \mathrm{mL}$, respectively. CS-hEPS was more active against superoxide than hydroxyl radicals; however, its activity was weaker than that of ascorbic acid.

3.3. In Vivo Antifatigue Effects of CS-hEPS from $H$. borinquense. The data obtained from various tests measuring the antifatigue activity of CS-hEPS is represented in Figure 4. As shown in Figure 4(a), the average exhaustive swimming time of mice group at doses of 100, 150, and $200 \mathrm{mg} / \mathrm{kg}$, respectively, was significantly $(P<0.01)$ prolonged compared to mice of the negative control group (saline solution). Exhaustive swimming time of every treatment group of CS-hEPS at doses of 100, 150, and $200 \mathrm{mg} / \mathrm{kg}$ was $161.75 \pm 4.25,175.83 \pm 5.75$, and $194.50 \pm 6.35$ seconds (sec), respectively. CS-hEPS groups of mice had extended exhaustive swimming time by $36.90,48.81$, and $64.62 \%$, respectively, compared to mice treated with saline solution (negative control group).

Then, the exhaustive swimming fatigue-related biochemical parameters in mice (SUN, LDH, and HG) were measured. As demonstrated in Figure 4(b), SUN levels of CS-hEPS groups $(100,150,200 \mathrm{mg} / \mathrm{kg})$ were $27.25 \pm 3.06$, $22.59 \pm 3.13$, and $23.75 \pm 2.52 \mathrm{mmol} / \mathrm{L}$, respectively, which were reduced significantly $(P<0.01)$ by $58.09,65.26$, and $63.47 \%$, respectively, compared to the negative control group (saline solution).

The data from Figure 4(c) indicated that HG contents of two treatment CS-hEPS groups, CS-hEPS-150 and CShEPS-200, were significantly higher $(P<0.01)$ than the negative control group. Contents of HG in CS-hEPS-150 and CS-hEPS-200 groups were $5.66 \pm 0.90$ and $5.81 \pm 0.75 \mathrm{mg} / \mathrm{g}$, which increased by 56.35 and $60.49 \%$, respectively, compared to the group treated with saline solution (negative control group) (3.62 $\pm 0.66 \mathrm{mg} / \mathrm{g})$. However, HG level of CShEPS-100 group was $3.28 \pm 0.48 \mathrm{mg} / \mathrm{g}$ remaining lower than that observed in the negative control group. It appears that 


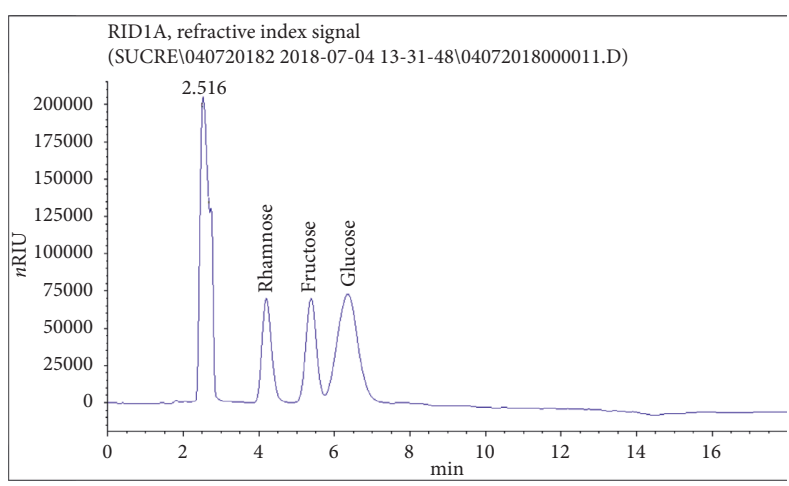

(a)

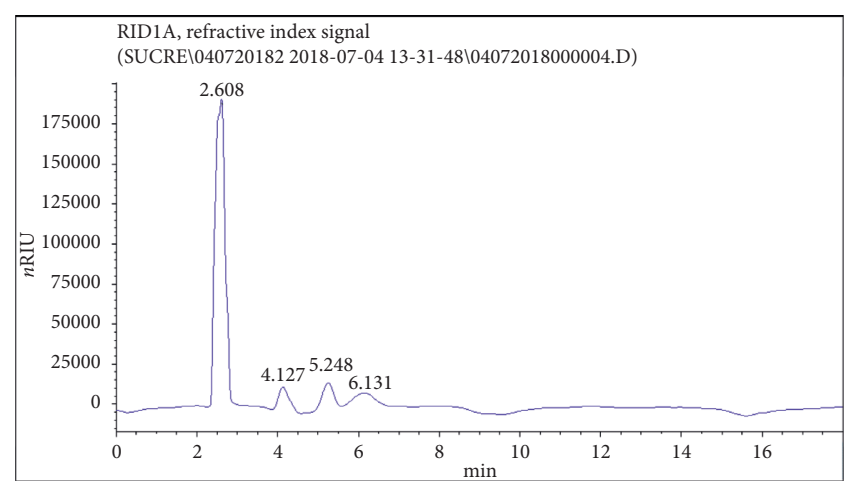

(b)

FIgURE 1: HPLC-RID chromatogram of (a) standard monosaccharides (rhamnose, fructose, and glucose) and (b) CS-hEPS hydrolysate.

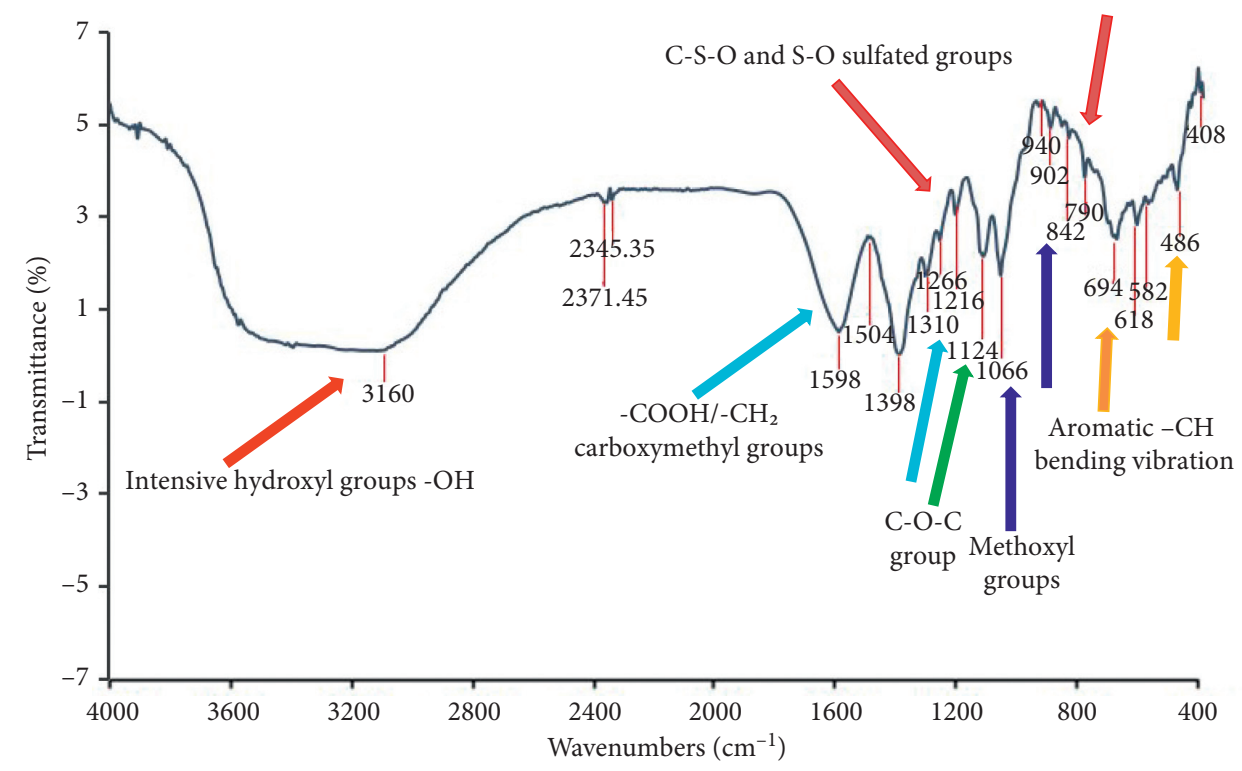

FIGURE 2: FTIR spectrum of H. borinquense purified CS-hEPS sample over a wave number range of $400-4000 \mathrm{~cm}^{-1}$.

the $100 \mathrm{mg} / \mathrm{kg}$ dose of CS-hEPS would remain insufficient to cover the hepatic glycogen deficiency of mice group CShEPS-100. Moreover, Figure 4(d) indicated that 30-day CShEPS treatment reduced by $5.57 \%$ (at a dose of $100 \mathrm{mg} / \mathrm{kg}$ ), $7.81 \%$ (at a dose of $150 \mathrm{mg} / \mathrm{Kg}$ ), and $11.25 \%$ (at a dose of $200 \mathrm{mg} / \mathrm{kg})$ the serum LDH activity in mice $(P<0.05)$.

3.4. In Vitro Antitumor Activity of CS-hEPS from $H$. borinquense. The antitumor activity of CS-hEPS against myelogenous leukemia K562 and liver cancer Hep G cells at different incubation periods and concentrations is summarized in Figures 5(a) and 5(b). As shown in Figure 5(a), inhibition effects of CS-hEPS on myelogenous leukemia K562 cells significantly $(P<0.05)$ increased along with the increasing concentrations and treatment time. At the lowest concentration $(50 \mu \mathrm{g} / \mathrm{mL})$ and treatment period $(24 \mathrm{~h})$, the inhibition rate was $17.2 \pm 0.26 \%$. Following the treatment with the highest concentration $(600 \mu \mathrm{g} / \mathrm{mL})$ and at the longest treatment period $(72 \mathrm{~h})$, the inhibition rate significantly $(P<0.05)$ improved $(86.6 \pm 0.32 \%)$ and became very close to the positive control 5 -FU $(91.4 \pm 0.14 \%)$. The antitumor activity of CS-hEPS against liver cancer HepG cells was also demonstrated in terms of dose and incubation time (Figure 5(b)). The highest inhibition rate was $58.6 \pm 0.43 \%$ obtained at $600 \mu \mathrm{g} / \mathrm{mL}$ and $72 \mathrm{~h}$ of incubation.

\section{Discussion}

Although very diversified with a great number of species, luckily, no member of the domain Archaea has been described as a pathogen for humans, animals, or plants [31, 32]. The CS-hEPS produced by the archaeon $H$. borinquense was similar to other microbial EPS with respect to crude chemical and mainly monosaccharide composition. Interestingly, it exhibited peculiar chemical characteristics, such as high uronic acid and sulfate contents, and importantly specific functional units, such as carboxymethyl, methoxyl, 


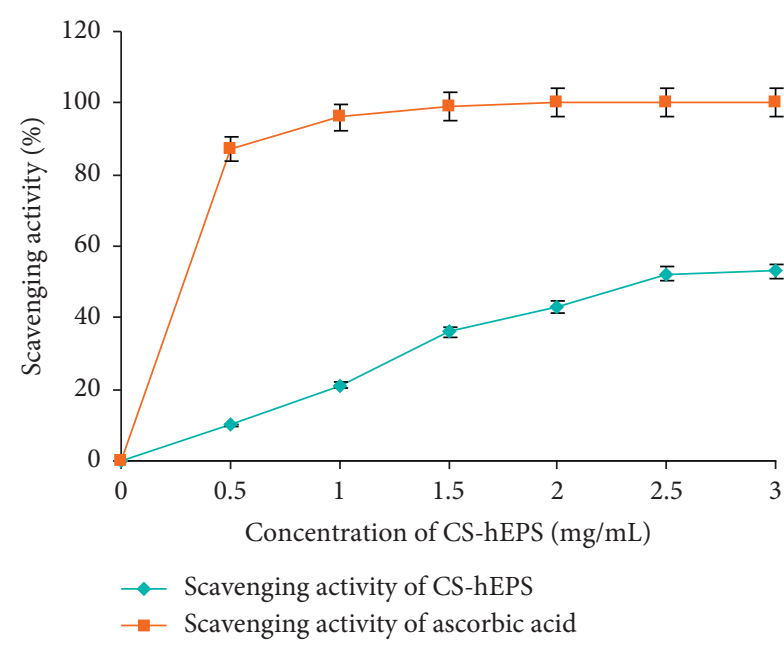

(a)

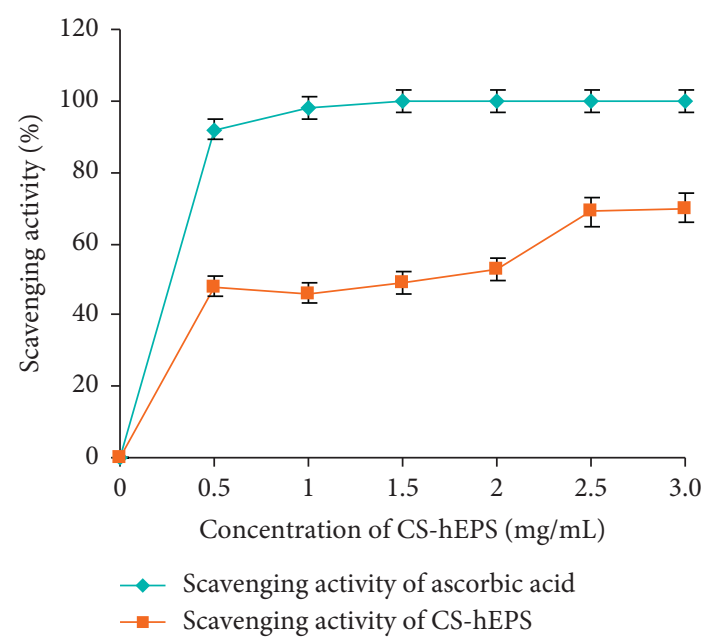

(b)

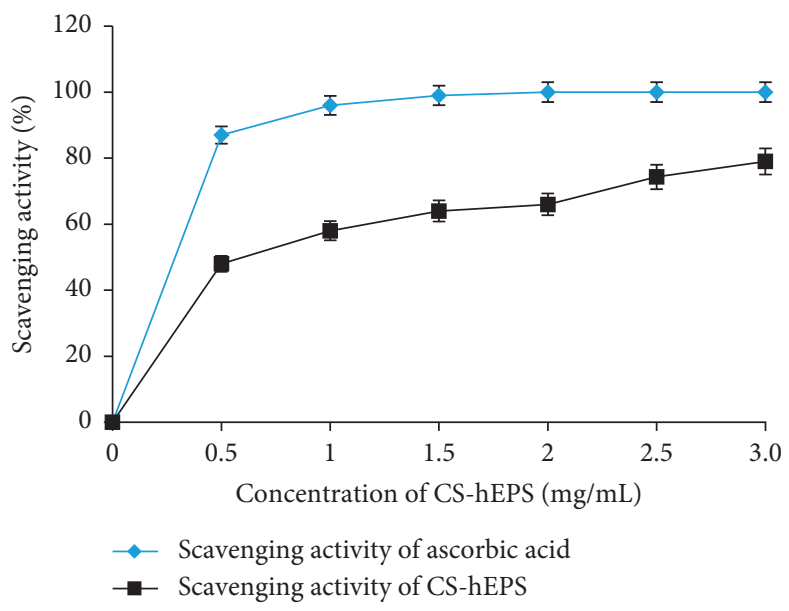

(c)

FIGURE 3: (a) DPPH radical scavenging activity, (b) hydroxyl radical scavenging activity, and (c) superoxide radical scavenging activity of the CS-hEPS from $H$. borinquense and control standards. Results are expressed as a mean \pm SD $(n=3)$.

and sulfated groups. Sulfated and/or carboxymethylated EPS have attracted attention in the field of pharmacology for their valuable biological activities [30, 33, 34]. Moreover, carboxymethylation and sulfation were applied to chemically modify polysaccharides for enhancing their bioactivities [33, 34].

In this study several in vitro and in vivo methods have been used to evaluate the bioactivity (antioxidant, antifatigue, and antitumoral activities) and to assess the potential of CS-hEPS of an archaeon to be applied as harmless adjuvants in human cancer therapy. In order to obtain a candidate antioxidant that would be of benefit to human health $[35,36]$, CS-hEPS antioxidant potential was investigated through hydrogen atom transfer and single electron transfer methods $[3,37]$.

Among these methods, the DPPH free radical has been widely adopted as a tool for estimating the free radical scavenging activities of antioxidants $[38,39]$. A lower absorbance of the reaction mixture indicates a higher DPPH radical scavenging activity. In this work, the radical scavenging activities on DPPH exhibited an obvious concentration dependency within the range of tested concentrations (Figure 3(a)). These findings indicated that CS-hEPS had significant scavenging activity with an $\mathrm{IC}_{50}$ equal to $2.5 \mathrm{mg} / \mathrm{mL}$. Previous studies evaluated radical scavenging activities of EPS from different species. CS-hEPS showed similar activity to that of $C$. pyrenoidosa EPS ( IC $_{50}, 2.14 \mathrm{mg} /$ $\mathrm{mL}$ ) and better activities than that of Lactobacillus plantarum C88 EPS (52.2\% at $4.0 \mathrm{mg} / \mathrm{mL})$ and Pseudomonas fluorescens EPS $(30.0 \%$ at $1.0 \mathrm{mg} / \mathrm{mL})$ [40-42].

Additionally, hydroxyl and superoxide radicals as primary ROS are considered as the most contributors of oxidative stress. They are the most harmful species of free radicals that may cause severe damage to cells, even DNA and protein, and lead to various disorders such as cancer and fatigue. Therefore, scavenging these radicals is important for protecting physiological systems. Interestingly, CS-hEPS exhibited considerable scavenging activities against hydroxyl and superoxide radicals in a concentration-dependent manner and could be explored as a potential antioxidant 


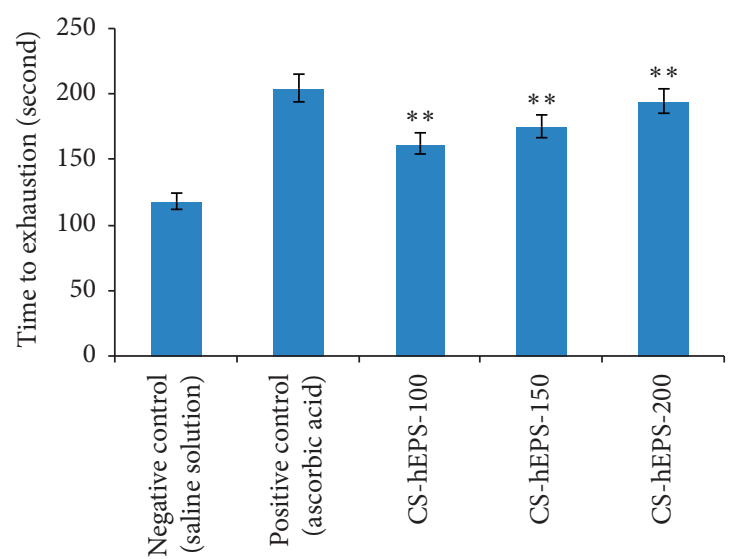

(a)

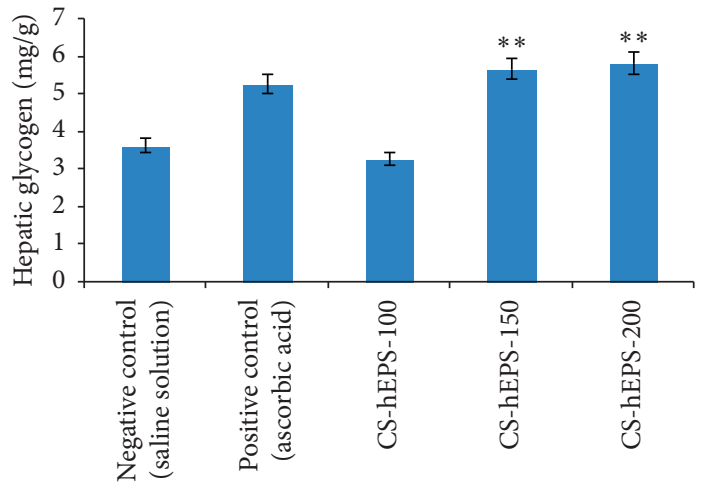

(c)

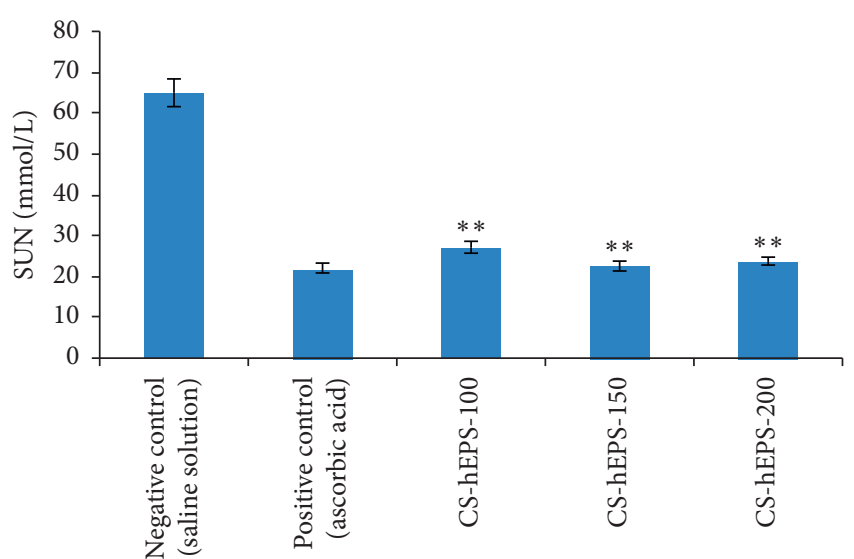

(b)

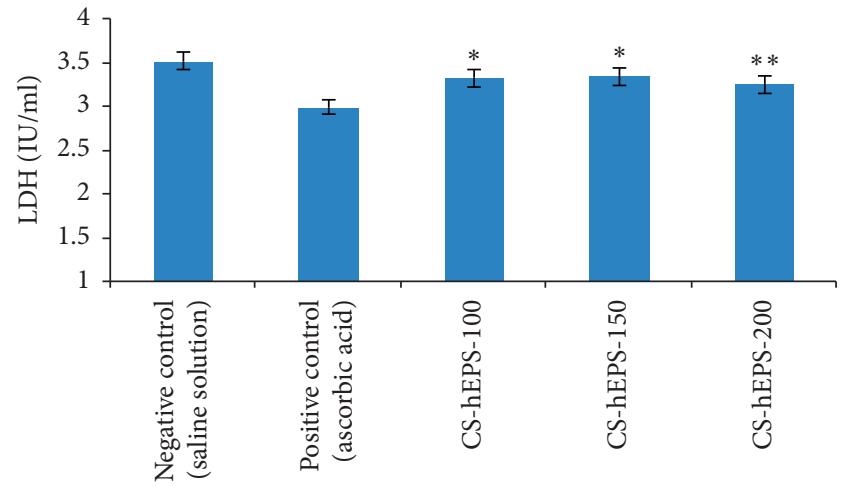

(d)

FIGURE 4: Effect of administrations of $H$. borinquense purified CS-hEPS on (a) swimming exercise performance. The endurance of mice was measured after 30 days of CS-hEPS administration by an exhaustive swimming exercise, (b) SUN, (c) hepatic glycogen, (d) LDH levels at the end of the experiments. Data are presented as mean \pm SD $(n=20)$.

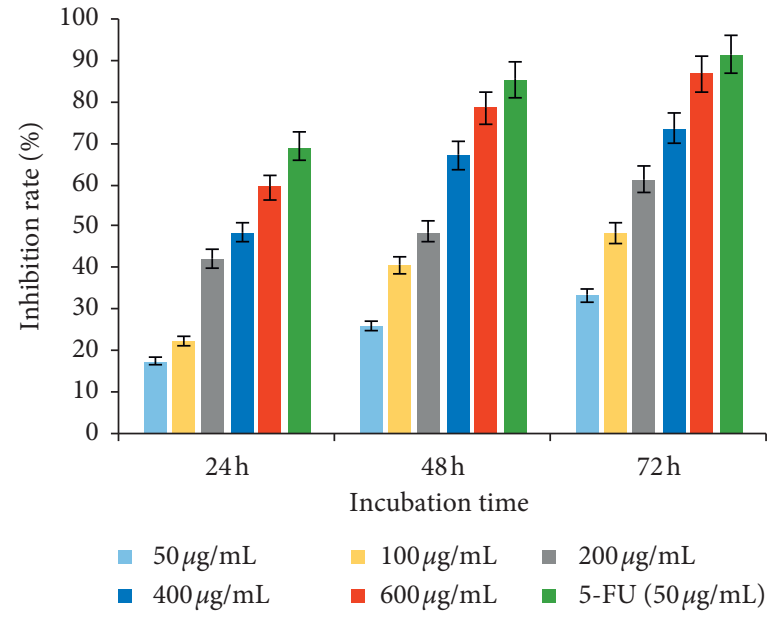

(a)

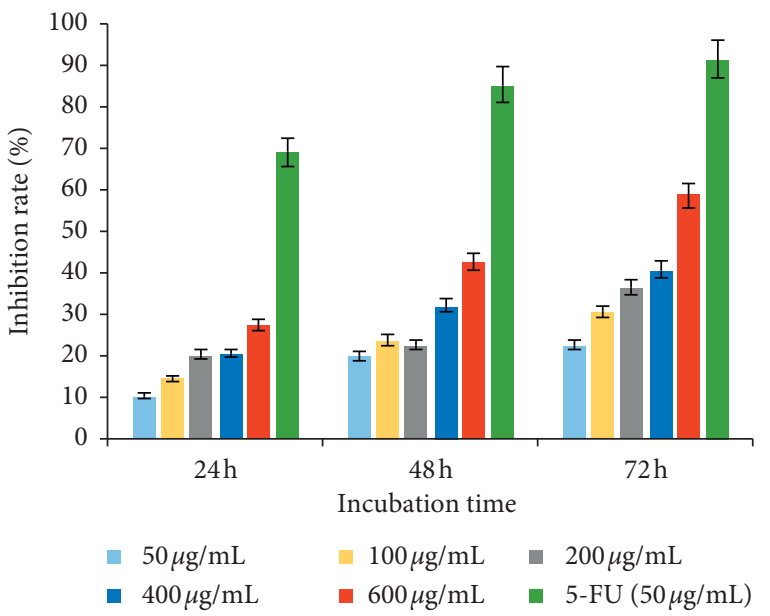

(b)

FIGURE 5: Antitumor effects of $H$. borinquense purified CS-hEPS on myelogenous leukemia cells K562 (a) and liver cancer Hep G (b) cells. All values were expressed as means \pm SD of three replications.

agent. By comparing $\mathrm{IC}_{50}$ values, CS-hEPS showed better activities on hydroxyl and superoxide radicals than that on DPPH (Figures $3(\mathrm{a})-3(\mathrm{c}))$. IC 50 values for these radicals were 1.5 and $0.5 \mathrm{mg} / \mathrm{mL}$, respectively. Additionally, CS-
hEPS demonstrated similar hydroxyl radical scavenging capacity to Lactobacillus gasseri FR4 EPS ( IC $_{50}, 1.58 \mathrm{mg} / \mathrm{mL}$ ) [43] and lower capacity than Scenedesmus sp. EPS ( $\mathrm{IC}_{50}$, $0.38 \mathrm{mg} / \mathrm{ml})[40]$. 
It has been reported that the antioxidant activity of polysaccharides is closely linked to their physiochemical properties and functional groups, mainly the uronic acid and sulfate contents $[3,21,44,45]$. In the present study, CS-hEPS contained a significant proportion of uronic acid and sulfate. The presence of sulfate groups could activate the hydrogen atom of the anomeric carbon and lead to stronger atom donating capacities [46, 47]. Additionally, hydrogen atoms from all ring $\mathrm{CH}$ bonds on carbohydrate contribute to the radical scavenging ability and act as electron or hydrogen donors to scavenge free radicals and consequently exhibit an antioxidant activity [48, 49].

Taking into account the above results, which suggested that CS-hEPS had the potential to be an effective scavenger for hydroxyl and superoxide radicals, our results are also concordant with a previous report that showed that a polysaccharide from Bacillus licheniformis BLP2 [47], with more sulfate groups (6.17\%), had higher in vitro scavenging abilities. Thus, it is legitimate to suggest that sulfate groups play an important role in the scavenging of free radicals. CShEPS had higher scavenging ability due to its carboxymethyl, methoxyl, and sulfated groups, which is in agreement with the FTIR analysis and the sulfate content. These groups were described in previous studies as free radical scavengers [50-52]. However, all these studies described the effect of chemically modified polysaccharides and so none of these works examined the combined effect of carboxymethyl, methoxyl, and sulfated groups on the bioactivity of polysaccharides. Moreover, interestingly, all these three types of functional groups are naturally available in CS-hEPS.

With regard to the antifatigue activity, an exhaustive weight loaded swimming test was performed to evaluate the degree of physical fatigue in mice following 30 days of oral treatment by CS-hEPS at different doses. Swimming time to exhaustion is an appropriate parameter to reveal the endurance capacity of mice and gives a high reproducibility to measure the degree of fatigue [29]. CS-hEPS groups of mice had extended exhaustive swimming time at doses of 100 , 150 , and $200 \mathrm{mg} / \mathrm{kg}$ by $36.90,48.81$, and $64.62 \%$, respectively, compared to mice treated with saline solution (Figure 4(a)), which indicated that CS-hEPS exhibited an antifatigue effect. Previous studies have attempted to identify antifatigue polysaccharides to delay fatigue and accelerate the elimination of tiredness. CS-hEPS showed better effects of relieving fatigue (64.62\%) than Abelmoschus esculentus EPS (30.5\%) [53].These effects are similar to Gynostemma pentaphyllum polysaccharide (GPP) which significantly prolonged exhaustive exercise time of mice. According to Chi et al. [54], the underlying mechanisms by which GPP exerts its antifatigue effect may be associated with the role of this polysaccharide in scavenging excessive free radicals produced during physical exercise.

Fatigue-related biochemical parameters in mice, notably SUN, LDH, and HG, were measured to validate and elucidate the underlying mechanisms of the antifatigue activity of CS-hEPS. Metabolic dysregulation involves the exhaustion of energy sources, such as HG. Consequently, the accumulation of metabolites, such as SUN, and the generation of free radicals contribute to fatigue. Moreover, the accumulation of lactic acid during intensive exercise causes decrease in $\mathrm{pH}$ of muscles and blood, which inhibits muscle contraction and induces fatigue $[18,55,56]$. Under normal conditions, muscular LDH catalyzes the mutual transformation of lactic acid and pyruvate. A high serum LDH level is also a marker of muscle damage; it is therefore a relevant indicator of fatigue after exercise. When energy sources derived from carbohydrates and fats are depleted, the organism invokes the catabolism of proteins and amino acids $[35,57]$. Consequently, the excess production of SUN will reflect the protein decomposition which will attenuate the muscle contraction and induce fatigue. SUN level will significantly increase when body is poorly adapted for exercise tolerance $[33,56]$. In this study, after the exhaustive swimming (Figure 4(b)), SUN levels of CS-hEPS groups $(100,150,200 \mathrm{mg} / \mathrm{kg})$ were reduced significantly $(P<0.01)$ by $58.09,65.26$, and $63.47 \%$, respectively, compared to the group treated with saline solution. CS-hEPS reduced SUN level better than LEP-1b polysaccharide from Lachnum $(19.77 \%$ at $200 \mathrm{mg} / \mathrm{kg}$ ) [33]. Two mechanisms could explain these results: (1) CS-hEPS decrease protein catabolism and therefore maximize the exhaustive swimming time and/or (2) CS-hEPS improve hepatic glycogenesis which in turn controls protein catabolism. It is widely accepted that the endurance of the body depends on the level of energy source including $\mathrm{HG}$ and rapid consumption of hepatic glycogen resulting in a decrease in the body's workload capacity. Thus, restoring the level of $\mathrm{HG}$ is essential to counteract fatigue and improve physical performance. Results from Figure 4(c) indicated that, after the swimming test, HG contents of two treatment groups, CS-hEPS-150 and CS-hEPS-200, were significantly higher $(P<0.01)$ than saline solution-treated group. Contents of HG increased by 56.35 and $60.49 \%$, respectively. These results argue in favor of the second above-mentioned proposed mechanism in which CS-hEPS from $H$. borinquense could reduce the catabolic metabolism of proteins by restoring the liver energy reservoir. Similarly, Surhio et al. [33] demonstrated that EPS from Lachnum LEP-1b increased the content of hepatic glycogen in mice $(21.89 \%$ at $200 \mathrm{mg} / \mathrm{kg})$. However the glycogenesis activity of CS-hEPS was significantly higher than that of LEP-1b at the same doses. This is due to functional groups of CS-hEPS, particularly, carboxymethyl, methoxyl, and sulfated groups (Figure 2).

$\mathrm{LDH}$ is recognized as a reliable parameter of muscle physiological activity, and, normally, it is localized in the cytosol. An increase in its serum level indicates that muscle damage has occurred. LDH oxidizes lactic acid, restores the $\mathrm{pH}$ value, and heals lactic acid damage [29].

In this study, daily oral administration of CS-hEPS for 30 days significantly $(P<0.05)$ reduced serum LDH activity in mice $(11.25 \%$ at $200 \mathrm{mg} / \mathrm{kg}$; Figure $4(\mathrm{~d}))$ as compared with the saline solution-treated group.

In summary an exhaustive swimming test was applied to study the antifatigue activity which demonstrated that each treatment group CS-hEPS extended exhaustive swimming time in mice. In addition oral treatment with CS-hEPS increased the exercise tolerance, boosted the HG level by activating the energy metabolism, and reduced the 
accumulation of SUN and LDH contents during exercise, which could prolong the exercise durability. Due to the particularities of its chemical structure, CS-hEPS showed better antifatigue effects than those of previously reported polysaccharides $[33,53,54,58]$.

The antitumor activity of CS-hEPS has also been tested against two types of cancer cell lines, myelogenous leukemia K562 and liver cancer Hep G cells, at different incubation periods and doses using 5 -fluorouracil molecule (5-FU) as a positive control. The inhibition rate against $\mathrm{K} 562$ cell line significantly improved at the highest concentration of CSEPS $(86.6 \pm 0.32 \%$ at $600 \mu \mathrm{g} / \mathrm{mL}$ and $72 \mathrm{~h}$ of treatment $)$ and became very close to the positive control 5-FU $(91.4 \pm 0.14 \%)$ (Figure 5(a)). In an earlier report, Chen et al. [30] reported three fractions, OCAP-2-2, OCAP-3-1, and OCAP-3-2, of polysaccharides from Ornithogalum caudatum that significantly inhibited the growth of K562 cells, when treated for $24 \mathrm{~h}$, at concentrations from 0.01 to $100 \mu \mathrm{g} / \mathrm{ml}$. OCAP-3-2 exhibited significantly higher inhibition activity than other fractions at all concentrations. The highest inhibition activity of OCAP-3-2 was $47.83 \pm 6.15 \%$ at the concentration of $0.1 \mu \mathrm{g} / \mathrm{ml}$. At concentration of $100 \mu \mathrm{g} / \mathrm{ml}$, inhibition activities of OCAP-3-1 and OCAP-3-2 were $14.69 \pm 3.57$ and $24.61 \pm 12.43 \%$, respectively. These results suggest that CShEPS has significant inhibition effects on leukemia K562 cells.

For the second cell line, liver cancer HepG cells, the highest inhibition rate by CS-hEPS was $58.6 \pm 0.43 \%$ obtained at $600 \mu \mathrm{g} / \mathrm{mL}$ and $72 \mathrm{~h}$ of incubation (Figure 5(b)). From previous literature, CS-hEPS inhibition rate was better than that obtained by polysaccharides from Cordyceps militaris $(57.11 \%$ at $8 \mathrm{mg} / \mathrm{mL}$ and $72 \mathrm{~h}$ of incubation) [59]. The inhibition rate is also close to that obtained by polysaccharide from Phellinus baumii which suppresses the HepG-2 cells proliferation by $61.2 \%$ at $400 \mu \mathrm{g} / \mathrm{mL}$ and $48 \mathrm{~h}$ of treatment period [60]. It is quite clear from our findings that CS-hEPS are more effective against myelogenous leukemia K562 cells, with similar antiproliferative effect of 5-FU, but with doses 8 to 12 times higher than that of 5-FU. Chemical modifications of polysaccharides by carboxymethylation or sulfation were applied in previous works for boosting their antiproliferative activities [61, 62]. Chen et al. [63], interested in the chemical modification by simultaneous carboxymethylation and sulfation processes of a native polysaccharide isolated from Poria cocos, obtained a modified polysaccharide with significantly higher inhibition ratio to Sarcoma 180 tumor in BALB/c mice compared to the nonmodified polysaccharide. These data confirmed that the antiproliferative efficacy of CS-hEPS against cancerous cell lines could be attributed to their structural characteristics, in particular carboxymethyl and sulfated groups.

Previous studies demonstrated that some microbial polysaccharides fight cancer cells through different mechanisms such as cell cycle interruption, induction of apoptosis, collapse of membrane potential, poly-ADP-ribose polymerase (PARP) cleavage, and expression of many tumor suppressor genes such as Bax, Cas-3, Bcl-2, and p53 [64-66]. In this context, Ruiz-Ruiz et al. [64] explored the influence of the sulfate group on the antitumoral activity of EPS by modifying them up to saturation and then by depriving them of their constitutive native sulfates. The authors have found that the sulfated EPS induced high apoptosis hematopoietic tumor T cell lines. Apoptosis induction has been confirmed through activation and inhibition of the caspase gene and change in the mitochondrial membrane potential [64]. Li et al. [66] investigated the molecular mechanism involved in the antitumor activity of EPS from Ganoderma atrium against tumor growth in S180-bearing mice. They found that the induction of apoptosis was achieved through mitochondrial pathways and immunoenhancement properties. With regard to the CS-hEPS antitumoral mechanism, taking into account its structural properties, it might be pertinent to suggest that functional groups would allow CS-hEPS to bind and interact with cell targets, hence the induction of apoptosis probably through the cross-linking of multiple intracellular signals. Based on our results, a substantive work should be done to elucidate the antitumor mechanism of CShEPS.

Altogether, it was demonstrated that CS-hEPS from the archaeal strain $H$. borinquense exhibit valuable biological activities (antioxidant, antifatigue, and antitumoral activities) that could alleviate physiological disturbances in cancer patients including fatigue, ROS, stress, and even tumor cell suppression.

\section{Conclusion}

In this study, we have confirmed that $H$. borinquense CShEPS induce fatigue recovery via retarding the accumulation of SUN, restoring the level of $\mathrm{LDH}$, and enhancing the hepatic glycogen level. The in vitro antioxidant activity demonstrated that CS-hEPS could suppress oxidative stress, which could be another action pathway of its antifatigue effects. These findings with consideration of its antitumor activity argue in favor of a possible application of CS-hEPS as a novel natural adjuvant against cancer. In-depth structural characterization (e.g., NMR) and studies on animal cancer models will be conducted to validate the antitumor mechanism of CS-hEPS.

\section{Abbreviations}

Akt/PI3K:

Bax, Cas-3, Bcl-2, and p53:

CS-hEPS:

DPPH:

DSR:

EGF:

EST:

FTIR:

GPP:

HepG:
Protein kinase $\mathrm{B}$ (PKB), also known as Akt/ phosphatidylinositol-3-kinase Tumor suppressor genes encoded proteins that normally function to prevent tumor development Carboxymethylated sulfated heteroexopolysaccharide 1,1-Diphenyl-2-picrylhydrazyl DPPH scavenging rate Epidermal growth factor Exhaustive swimming test Fourier Transform InfraRed Gynostemma pentaphyllum polysaccharide Liver cancer cells 


$\begin{array}{ll}\text { HG: } & \text { Hepatic glycogen } \\ \text { HSR: } & \text { Hydroxyl radical scavenging rate } \\ \text { K562: } & \text { Myelogenous leukemia cells } \\ \text { LDH: } & \text { Lactic dehydrogenase } \\ \text { mEPS: } & \text { Microbial exopolysaccharide } \\ \text { MTT: } & \text { (3-(4,5-dimethylthiazol-2-yl)-2,5- } \\ & \text { diphenyltetrazolium bromide) } \\ \text { Mw: } & \text { Molecular weight } \\ \text { NADH: } & \text { Nicotinamide adenine } \\ & \text { dinucleotide } \\ \text { NBT: } & \text { Nitroblue tetrazolium } \\ \text { NF-kB: } & \text { Nuclear factor kappa B } \\ \text { OS: } & \text { Oxidative stress } \\ \text { Poly (ADP-ribose) } & \text { Group of proteins implicated in } \\ \text { polymerase (PARP): } & \text { cellular processes such as DNA } \\ & \text { repair and apoptosis } \\ \text { PMS: } & \text { Phenazine methosulphate } \\ \text { ROS: } & \text { Reactive oxygen species } \\ \text { SSR: } & \text { Superoxide radical scavenging rate } \\ \text { SUN: } & \text { Serum urea nitrogen } \\ \text { TCA: } & \text { Trichloroacetic acid } \\ \text { TFA: } & \text { Trifluoroacetic acid } \\ \text { U87MG: } & \text { Glioblastoma cells } \\ \text { 5-FU: } & \text { 5-Fluorouracil. }\end{array}$

\section{Data Availability}

The data used to support the findings of this study are available from the corresponding author upon request.

\section{Conflicts of Interest}

No potential conflicts of interest were reported by the authors.

\section{Acknowledgments}

This work was supported by the Tunisian Ministry of Higher Education and Scientific Research in the ambit of the laboratory project LR11ES31.

\section{Supplementary Materials}

Figure 1: (A) glucose standard curve, (B) glucuronic acid standard curve, and (C) potassium sulfate standard curve plotted to estimate total carbohydrate, uronic acid, and sulfate contents in CS-EPS, respectively. (Supplementary Materials)

\section{References}

[1] C. Wang, S. Shi, Q. Chen et al., "Antitumor and immunomodulatory activities of Ganoderma lucidum polysaccharides in glioma-bearing rats," Integrative Cancer Therapies, vol. 17, no. 3, pp. 674-683, 2018.

[2] H. Chouchane, M. Neifar, N. Raddadi et al., "Microbial exopolysaccharides as alternative sources of dietary fibers with interesting functional and healthy properties," in Dietary Fiber: Production Challenges, Food Sources and Health
Benefits, M. E. Clemens, Ed., pp. 159-178, Nova Publishers, New York, NY, USA, 2015.

[3] J. Wang, S. Hu, S. Nie, Q. Yu, and M. Xie, "Reviews on mechanisms of in vitro antioxidant activity of polysaccharides," Oxidative Medicine and Cellular Longevity, vol. 2016, Article ID 5692852, 13 pages, 2016.

[4] Y.-T. Chen, Q. Yuan, L.-T. Shan, M.-A. Lin, D.-Q. Cheng, and C.-Y. Li, "Antitumor activity of bacterial exopolysaccharides from the endophyte Bacillus amyloliquefaciens sp.isolated from Ophiopogon japonicas," Oncology Letters, vol. 5, no. 6, pp. 1787-1792, 2013.

[5] C.-T. Liu, F.-J. Chu, C.-C. Chou, and R.-C. Yu, "Anti proliferative and anti cytotoxic effects of cell fractions and exopolysaccharides from Lactobacillus casei 01," Mutation Research/Genetic Toxicology and Environmental Mutagenesis, vol. 721, no. 2, pp. 157-162, 2011.

[6] Y. Murofushi, J. Villena, K. Morie et al., "The toll-like receptor family protein RP105/MD1 complex is involved in the immunoregulatory effect of exopolysaccharides from Lactobacillus plantarum N14," Molecular Immunology, vol. 64, no. 1, pp. 63-75, 2015.

[7] P. Priyanka, A. B. Arun, P. Ashwini, and P. D. Rekha, "Functional and cell proliferative properties of an exopolysaccharide produced by Nitratireductor sp. PRIM-31," International Journal of Biological Macromolecules, vol. 85, pp. 400-404, 2016.

[8] H. Liu, L. Zhou, S. Shi et al., "Oligosaccharide G19 inhibits U-87 MG human glioma cells growth in vitro and in vivo by targeting epidermal growth factor (EGF) and activating p53/ p21 signaling," Glycobiology, vol. 24, no. 8, pp. 748-765, 2014.

[9] S. A. Kestler and G. LoBiondo-Wood, "Review of symptom experiences in children and adolescents with cancer," Cancer Nursing, vol. 35, no. 2, pp. E31-E49, 2012.

[10] C. Baggott, M. Dodd, C. Kennedy et al., "An evaluation of the factors that affect the health-related quality of life of children following myelosuppressive chemotherapy," Supportive Care in Cancer, vol. 19, no. 3, pp. 353-361, 2011.

[11] E. Miller, E. Jacob, and M. J. Hockenberry, "Nausea, pain, fatigue, and multiple symptoms in hospitalized children with cancer," Oncology Nursing Forum, vol. 38, no. 5, pp. E382E393, 2011.

[12] L. C. Daniels, L. D. Brumley, and L. A. Schwartz, "Fatigue in adolescents with cancer compared to healthy adolescents," Pediatric Blood \& Cancer, vol. 60, no. 11, pp. 1902-1907, 2013.

[13] Y. Chen, P. Jungsuwadee, M. Vore, D. A. Butterfield, and D. K. St. Clair, "Collateral damage in cancer chemotherapy: oxidative stress in nontargeted tissues," Molecular Interventions, vol. 7, no. 3, pp. 147-156, 2007.

[14] L. A. A. Gilliam and D. K. St. Clair, "Chemotherapy-induced weakness and fatigue in skeletal muscle: the role of oxidative stress," Antioxidants \& Redox Signaling, vol. 15, no. 9, pp. 2543-2563, 2011.

[15] E. Birben, U. M. Sahiner, C. Sackesen, S. Erzurum, and O. Kalayci, "Oxidative stress and antioxidant defense," World Allergy Organization, vol. 5, no. 1, pp. 9-19, 2012.

[16] R. S. Farag, G. S. El-Baroty, and A. Basuny, "Safety evaluation of olive phenolic compounds as natural antioxidants," International Journal of Food Sciences and Nutrition, vol. 54, no. 3, pp. 159-174, 2003.

[17] R. S. Lanigan and T. A. Yamarik, "Final report on the safety assessment of BHT," International Journal of Toxicology, vol. 21, no. 2_suppl, pp. 19-94, 2002. 
[18] J.-J. Wan, Z. Qin, P.-Y. Wang, Y. Sun, and X. Liu, "Muscle fatigue: general understanding and treatment," Experimental \& Molecular Medicine, vol. 49, no. 10, p. e384, 2017.

[19] W. Xiaoming, L. Ling, and Z. Jinghang, "Antioxidant and anti-fatigue activities of flavonoids from puerariae radix," African Journal of Traditional", Complementary and Alternative Medicines, vol. 9, no. 2, pp. 221-227, 2012.

[20] H. Chouchane, A. Najjari, M. Neifar et al., "Unravelling the characteristics of a heteropolysaccharide-protein from an Haloarchaeal strain with flocculation effectiveness in heavy metals and dyes removal," Environmental Technology, pp. 116, 2018.

[21] S. Guesmi, H. Chouchane, M. Neifar, F. Hosni, A. Cherif, and H. Sghaier, "Radiation-inducible radioprotective exopolysaccharides of Bacillus siamensis CV5 from irradiated roots of Cistanche violacea to decrease free radical damage produced by ionizing radiation," International Journal of Radiation Biology, vol. 95, no. 11, pp. 1552-1563, 2019.

[22] W. Tang, M. Dong, W. Wang et al., "Structural characterization and antioxidant property of released exopolysaccharides from Lactobacillus delbrueckii ssp.bulgaricus SRFM-1," Carbohydrate Polymers, vol. 173, pp. 654-664, 2017.

[23] M. F. Chaplin and J. F. Kennedy, Carbohydrate Analysis, Oxford University Pres, New York, NY, USA, 2nd edition, 1994.

[24] N. Blumenkrantz and G. Asboe-Hansen, "New method for quantitative determination of uronic acids," Analytical Biochemistry, vol. 54, no. 2, pp. 484-489, 1973.

[25] K. S. Dodgson and R. G. Price, "A note on the determination of the ester sulphate content of sulphated polysaccharides," Biochemical Journal, vol. 84, no. 1, pp. 106-110, 1962.

[26] G. Zhang, L. He, and M. Hu, "Optimized ultrasonic-assisted extraction of flavonoids from Prunella vulgaris L. and evaluation of antioxidant activities in vitro," Innovative Food Science \& Emerging Technologies, vol. 12, no. 1, pp. 18-25, 2011.

[27] C. Wu, R. Chen, X. Wang, B. Shen, W. Yue, and Q. Wu, "Antioxidant and anti-fatigue activities of phenolic extract from the seed coat of Euryale ferox salisb. and identification of three phenolic compounds by LC-ESI-MS/MS," Molecules, vol. 18, no. 9, pp. 11003-11021, 2013.

[28] D. Qiao, C. Ke, B. Hu et al., "Antioxidant activities of polysaccharides from Hyriopsis cumingii," Carbohydrate Polymers, vol. 78, no. 2, pp. 199-204, 2009.

[29] L.-Z. Huang, B.-K. Huang, Q. Ye, and L.-P. Qin, "Bioactivityguided fractionation for anti-fatigue property of Acanthopanax senticosus," Journal of Ethnopharmacology, vol. 133, no. 1, pp. 213-219, 2011.

[30] R. Chen, F. Meng, Z. Liu, R. Chen, and M. Zhang, "Antitumor activities of different fractions of polysaccharide purified from Ornithogalum caudatum ait," Carbohydrate Polymers, vol. 80, no. 3, pp. 845-851, 2010.

[31] H. Sghaier, A. Najjari, and K. Ghedira, "Introductory chapter: a brief overview of archaeal applications," Archaea-New Biocatalysts, Novel Pharmaceuticals and Various Biotechnological Applications, H. Sghaier, A. Najjari, and K. Ghedira, Eds., pp. 1-10, 2017, In Tech.

[32] H. Cherif, M. Neifar, and H. Chouchane, "Extremophile diversity and biotechnological potential from desert environments and saline systems of southern Tunisia," in Extremophiles: From Biology to Biotechnology, V. Ravi, D. Durvasula, and V. Subba Rao, Eds., pp. 33-64, CRC Publishers, Boca Raton, FL, USA, 2018.
[33] M. M. Surhio, Y. Wang, S. Fang, J. Li, and M. Ye, “Anti-fatigue activity of a Lachnum polysaccharide and its carboxymethylated derivative in mice," Bioorganic \& Medicinal Chemistry Letters, vol. 27, no. 20, pp. 4777-4780, 2017.

[34] T. A. Olasehinde, L. V. Mabinya, A. O. Olaniran, and A. I. Okoh, "Chemical characterization of sulfated polysaccharides from Gracilaria gracilis and Ulva lactuca and their radical scavenging, metal chelating, and cholinesterase inhibitory activities," International Journal of Food Properties, vol. 22, no. 1, pp. 100-110, 2019.

[35] C.-T. Horng, J.-K. Huang, H.-Y. Wang, C.-C. Huang, and F.-A. Chen, "Antioxidant and antifatigue activities of polygonatum alte-lobatum hayata rhizomes in rats," Nutrients, vol. 6, no. 11, pp. 5327-5337, 2014.

[36] C. Sanchez-Moreno, "Review: methods used to evaluate the free radical scavenging activity in foods and biological systems," Food Science and Technology International, vol. 8, no. 3, pp. 121-137, 2002.

[37] J. B. L. Tan and Y. Y. Lim, "Critical analysis of current methods for assessing the in vitro antioxidant and antibacterial activity of plant extracts," Food Chemistry, vol. 172, pp. 814-822, 2015.

[38] K. Pyrzynska and A. Pękal, "Application of free radical diphenyl picrylhydrazyl (DPPH) to estimate the antioxidant capacity of food samples," Analytical Methods, vol. 5, no. 17, pp. 4288-4295, 2013.

[39] T. Noipa, S. Srijaranai, T. Tuntulani, and W. Ngeontae, "New approach for evaluation of the antioxidant capacity based on scavenging DPPH free radical in micelle systems," Food Research International, vol. 44, no. 3, pp. 798-806, 2011.

[40] J. Zhang, L. Liu, Y. Ren, and F. Chen, "Characterization of exopolysaccharides produced by microalgae with antitumor activity on human colon cancer cells," International Journal of Biological Macromolecules, vol. 128, pp. 761-767, 2019.

[41] L. Zhang, C. Liu, D. Li et al., "Antioxidant activity of an exopolysaccharide isolated from Lactobacillus plantarum C88," International Journal of Biological Macromolecules, vol. 54, pp. 270-275, 2013.

[42] A. R. Sirajunnisa, V. Vijayagopal, B. Sivaprakash, T. Viruthagiri, and D. Surendhiran, "Optimization, kinetics and antioxidant activity of exopolysaccharide produced from rhizosphere isolate, Pseudomonas fluorescens CrN6," Carbohydrate Polymers, vol. 135, pp. 35-43, 2016.

[43] R. P. Rani, M. Anandharaj, and A. David Ravindran, "Characterization of a novel exopolysaccharide produced by Lactobacillus gasseri FR4 and demonstration of its in vitro biological properties," International Journal of Biological Macromolecules, vol. 109, pp. 772-783, 2018.

[44] P. White, R. Oliveira, A. Oliveira et al., "Antioxidant activity and mechanisms of action of natural compounds isolated from lichens: a systematic review," Molecules, vol. 19, no. 9, pp. 14496-14527, 2014.

[45] L. Sun, L. Wang, J. Li, and H. Liu, "Characterization and antioxidant activities of degraded polysaccharides from two marine Chrysophyta," Food Chemistry, vol. 160, pp. 1-7, 2014.

[46] J. Li, Z. Chi, L. Yu, F. Jiang, and C. Liu, "Sulfated modification, characterization, and antioxidant and moisture absorption/ retention activities of a soluble neutral polysaccharide from Enteromorpha prolifera," International Journal of Biological Macromolecules, vol. 105, pp. 1544-1553, 2017.

[47] Z. Xu, G. Chen, L. Xue et al., "Isolation, structural characterizations and bioactivities of exopolysaccharides produced by Bacillus licheniformis," International Journal of Biological Macromolecules, vol. 141, pp. 298-306, 2019. 
[48] D. M. Kasote, S. S. Katyare, M. V. Hegde, and H. Bae, "Significance of antioxidant potential of plants and its relevance to therapeutic applications," International Journal of Biological Sciences, vol. 11, no. 8, pp. 982-991, 2015.

[49] Y. Lu, L. Xu, Y. Cong et al., "Structural characteristics and anticancer/antioxidant activities of a novel polysaccharide from Trichoderma kanganensis," Carbohydrate Polymers, vol. 205, pp. 63-71, 2019.

[50] X. T. Ma, X. Y. Sun, K. Yu, B. S. Gui, Q. Gui, and J. M. Ouyang, "Effect of content of sulfate groups in seaweed polysaccharides on antioxidant activity and repair effect of subcellular organelles in injured HK-2 cells," Oxidative Medicine and Cellular Longevity, vol. 2017, Article ID 2542950, 13 pages, 2017.

[51] L. Yang, T. Zhao, H. Wei et al., "Carboxymethylation of polysaccharides from Auricularia auricula and their antioxidant activities in vitro," International Journal of Biological Macromolecules, vol. 49, no. 5, pp. 1124-1130, 2011.

[52] N. Hristova-Avakumova, B. Nikolova-Mladenova, K. Yoncheva, and V. Hadjimitova, "Novel hydrazones antioxidant potential and stabilization via polysaccharide particles," Journal of Physics: Conference Series, vol. 780, 2017.

[53] Y.-X. Li, Z.-H. Yang, Y. Lin, W. Han, S.-S. Jia, and K. Yuan, "Antifatigue effects of ethanol extracts and polysaccharides isolated from Abelmoschus esculentus," Pharmacognosy Magazine, vol. 12, no. 47, pp. 219-224, 2016.

[54] A. Chi, L. Tang, J. Zhang, and K. Zhang, "Chemical composition of three polysaccharides from Gynostemma pentaphyllum and their antioxidant activity in skeletal muscle of exercised mice," International Journal of Sport Nutrition and Exercise Metabolism, vol. 22, no. 6, pp. 479-485, 2012.

[55] J. Liu, Z. Zhao, and Q. Han, "Research on antioxidation to delay fatigue," Dairy industries international, vol. 40, pp. 42-45, 2012.

[56] J. Wang, L. Liu, Q. Zhang, Z. Zhang, H. Qi, and P. Li, "Synthesized oversulphated, acetylated and benzoylated derivatives of fucoidan extracted from Laminaria japonica and their potential antioxidant activity in vitro," Food Chemistry, vol. 114, no. 4, pp. 1285-1290, 2009.

[57] H. I. Lo, D. Tsi, A. C. Tan, S. W. Wang, and M. C. Hsu, "Effects of postexercise supplementation of chicken essence on the elimination of exercise-induced plasma lactate and ammonia," Chinese Journal of Physiology, vol. 48, pp. 187-192, 2005.

[58] T. Ivanova, Y. Han, H.-J. Son, Y.-S. Yun, and J.-Y. Song, "Antimutagenic effect of polysaccharide ginsan extracted from Panax ginseng," Food and Chemical Toxicology, vol. 44, no. 4, pp. 517-521, 2006.

[59] A. Zhang, N. Zhang, D. Zhang, G. Zhang, and L. Teng, "Extraction, purification and antitumour activity of polysaccharide from mycelium of mutant Cordyceps militaris," Journal of Pharmaceutical Sciences, vol. 26, pp. 798-802, 2010.

[60] Q. Xue, J. Sun, M. Zhao, K. Zhang, and R. Lai, "Immunostimulatory and anti-tumor activity of a water-soluble polysaccharide from Phellinus baumii mycelia," World Journal of Microbiology and Biotechnology, vol. 27, no. 5, pp. 1017-1023, 2011.

[61] A. E. J. de Nooy, V. Rori, G. Masci, M. Dentini, and V. Crescenzi, "Synthesis and preliminary characterisation of charged derivatives and hydrogels from scleroglucan," Carbohydrate Research, vol. 324, no. 2, pp. 116-126, 2000.

[62] K. Zen, Y. Liu, D. Cairo, and C. A. Parkos, "CD11b/CD18dependent interactions of neutrophils with intestinal epithelium are mediated by fucosylated proteoglycans," The Journal of Immunology, vol. 169, no. 9, pp. 5270-5278, 2002.
[63] X. Chen, L. Zhang, and P. C. K. Cheung, "Immunopotentiation and anti-tumor activity of carboxymethylatedsulfated $\beta$-(1 $\longrightarrow 3)$-D-glucan from Poria cocos," International Immunopharmacology, vol. 10, no. 4, pp. 398-405, 2010.

[64] C. Ruiz-Ruiz, G. K. Srivastava, D. Carranza et al., "An exopolysaccharide produced by the novel halophilic bacterium Halomonas stenophila strain B100 selectively induces apoptosis in human T leukaemia cells," Applied Microbiology and Biotechnology, vol. 89, no. 2, pp. 345-355, 2011.

[65] W. A. Elkhateeb, G. M. Zaghlol, I. M. El-Garawani, E. F. Ahmed, M. E. Rateb, and A. E. Abdel Moneim, "Ganoderma applanatum secondary metabolites induced apoptosis through different pathways: in vivo and in vitro anticancer studies," Biomedicine \& Pharmacotherapy, vol. 101, pp. 264-277, 2018.

[66] W.-J. Li, Y. Chen, S.-P. Nie et al., "Ganoderma atrum polysaccharide induces anti-tumor activity via the mitochondrial apoptotic pathway related to activation of host immune response," Journal of Cellular Biochemistry, vol. 112, no. 3, pp. 860-871, 2011. 